Article

\title{
Increased Number of Spikelets per Panicle Is the Main Factor in Higher Yield of Transplanted vs. Direct-Seeded Rice
}

\author{
Wenxuan Mai ${ }^{1, *}$, Buhailiqem Abliz ${ }^{2}$ and Xiangrong Xue ${ }^{1}$ \\ 1 State Key Laboratory of Desert and Oasis Ecology, Xinjiang Institute of Ecology and Geography Chinese \\ Academy of Sciences, Urumqi 830011, China; xxr@ms.xjb.ac.cn \\ 2 Institute of Nuclear Technology and Biotechnology, Xinjiang Academy of Agricultural Sciences, \\ Urumqi 830091, China; halqam2006@163.com \\ * Correspondence: maiwx@ms.xjb.ac.cn; Tel.: +86-991-7823189
}

\section{check for}

updates

Citation: Mai, W.; Abliz, B.; Xue, X Increased Number of Spikelets per Panicle Is the Main Factor in Higher Yield of Transplanted vs.

Direct-Seeded Rice. Agronomy 2021, 11, 2479. https://doi.org/ 10.3390/agronomy11122479

Received: 25 October 2021

Accepted: 29 November 2021

Published: 6 December 2021

Publisher's Note: MDPI stays neutral with regard to jurisdictional claims in published maps and institutional affiliations.

Copyright: (c) 2021 by the authors. Licensee MDPI, Basel, Switzerland. This article is an open access article distributed under the terms and conditions of the Creative Commons Attribution (CC BY) license (https:// creativecommons.org/licenses/by/ $4.0 /)$.

\begin{abstract}
With increasing water shortages and labor costs, rice planting is gradually undergoing a transformation from traditional transplanting to direct seeding. However, the yield of direct-seeded rice is unstable and the reasons for this instability are disputed. Therefore, we established a field experiment conducted over 3 years to investigate the reasons for the difference in rice yield under different planting methods. The planting methods compared were transplanting (TR), broadcast sowing (BS), and sowing in line (SL). The yield of rice under TR was higher $\left(10,390 \mathrm{~kg} \mathrm{ha}^{-1}\right)$ than that of BS (7790.7 $\left.\mathrm{kg} \mathrm{ha}^{-1}\right)$ and SL (9105.2 $\left.\mathrm{kg} \mathrm{ha}^{-1}\right)$. Given that the harvest index showed little variation among the three planting methods, the yield differences reflected that shoot dry matter production under TR was higher. Two reasons for the latter observation are suggested: (1) the planting density under TR was lower than that under BS and SL, thus competition for nutrient resources would have been reduced; (2) the growth period of TR was longer. The higher shoot dry matter accumulation under TR contributed to enhanced panicle number per $\mathrm{m}^{2}$ and number of spikelets per panicle than under BS. A significant correlation between number of spikelets per panicle and yield was observed. Although yield was highest under TR, the costs under TR were the highest among the three planting methods. In contrast, the benefit-to-cost ratio under SL was higher than that of TR and BS. The higher yield under TR reflected the production of larger spikelets per panicle than those produced under direct-seeding methods. However, the benefits of SL are conducive to enhanced profitability of rice production.
\end{abstract}

Keywords: rice; direct seeding; dry matter; yield component

\section{Introduction}

Rice (Oryza sativa L.) is one of the most important grain crops in the world, accounting for $27 \%$ of the global grain yield [1]. Rapid population growth and economic development are escalating the demand for increased food production. Global rice production must increase by more than $1.2 \%$ annually to meet the growing demand for food [2]. In Asia, rice production is required to increase by $43 \%$ over the next 30 years to meet the food requirements of an increasing population [3]. The possibility of future expansion of the rice production area is limited. To meet the increasing demand for grains as a result of population growth, increasing the rice yield per unit area remains a critical problem to be addressed [4].

In addition to breeding high-yielding rice cultivars, rice yields are also largely affected by management practices [5]. There relative contributions of breeding and crop management to rice yield increase has shifted to 0.3:0.7 [6]. Therefore, management measures or planting methods play an extremely important role in the improvement of rice yield. Technological developments have contributed to the proliferation of cultivation techniques around the world, of which there are two basic planting methods: (1) direct seeding, which includes broadcast sowing (BS) and sowing in line (SL), and (2) transplanting of seedlings 
(TR; manually or mechanically). Traditionally, rice is planted by TR, but the planting method differs among regions, with a larger area of direct seeding apparent in developing areas. In recent years, owing to the continuous increase in labor costs, rice planting has gradually shifted from TR to direct seeding because of the reduced labor requirements and lower costs [7-9]. Taking Zhejiang Province, China as an example, in 2017, the rice planting area was $828,500 \mathrm{hm}^{2}$, of which the transplanting area and direct seeding area accounted for $60 \%$ and $40 \%$, respectively, while the direct seeding was mainly BS (81.6\%) and SL accounted for only $18.4 \%$ [10].

Distinct differences in rice yield are observed under different planting methods. Some research shows that the rice yield under BS is higher than that of TR [11,12]. Enhanced shoot dry matter production and a high spikelet number per panicle are considered to be associated with high grain yield under BS, but results are inconsistent [13,14]. Directseeded rice shows favorable changes in parameters that improve yield in comparison with those under TR, including earlier seedling emergence [15], stronger root activity, higher percentage seed set, and enhanced dry matter production at early developmental stages [14]. However, some studies show that the yield of TR is higher than that of BS rice [16-19]. Chen suggested that the lower grain yield of BS relative to TR rice is attributable to an excessive number of tillers formed during early development, lower leaf dry matter, and the photosynthetic rate at advanced developmental stages [16].

Rice yield is determined by sink size, namely the number of spikelets per $\mathrm{m}^{2}$, percentage seed set, and 1000-grain weight. Sink size is considered to be the primary determinant of grain yield in rice because of the stability in percentage seed set and 1000-grain weight of modern rice cultivars [20]. Sink size can be enhanced either by increasing the panicle number per $\mathrm{m}^{2}$ or the number of spikelets per panicle, or both. However, achieving an increase in both of these yield components is not easy because of a strong compensatory mechanism between the two yield components [21]. Therefore, a higher yield is generally achieved either by increasing panicle number per $\mathrm{m}^{2}$ or spikelet number per panicle. In addition, the performance of yield components varies across environments [22,23]. Different planting methods alter the growth environment of rice. A series of experiments have proved that yield component performance can be affected by planting method [16,17]. Therefore, we hypothesized that higher rice yield can be attained under TR compared with direct seeding primarily because the number of spikes per $\mathrm{m}^{2}$ or the spikelet number per panicle are higher under TR.

The rate of grain growth of field crops is initially slow, then enters a linear phase of rapid growth, and ultimately declines with approaching maturity. Grain filling, the final process associated with yield performance, is a crucial determinant of grain yield in cereal crops [24]. In this study, we established a 3-year field experiment that included three different rice planting methods, namely BS, SL, and TR. We focused on monitoring the growth and development of rice after the heading stage under the different planting methods. The main objectives were (1) to compare grain yield under the different planting methods, (2) to determine reasons for differences in grain yield under the different planting methods, and (3) to evaluate the income achieved under the different planting methods.

\section{Materials and Methods}

The field experiment was carried out in Moyu County, the main irrigated riceproducing area in Xinjiang, China, during the 2015, 2016, and 2017 cropping seasons. The site has an arid climate typical of the area, with average annual rainfall of $37 \mathrm{~mm}$, annual evaporation of $2239 \mathrm{~mm}$, and 2655 annual sunshine hours. The annual average temperature is $11.3^{\circ} \mathrm{C}$, the highest temperature is recorded in July (average for July $24.8^{\circ} \mathrm{C}$ ), the accumulated temperature $\geq 10^{\circ} \mathrm{C}$ is $4130^{\circ} \mathrm{C}$, and there are 210 frost-free days per year (Figure 1). 


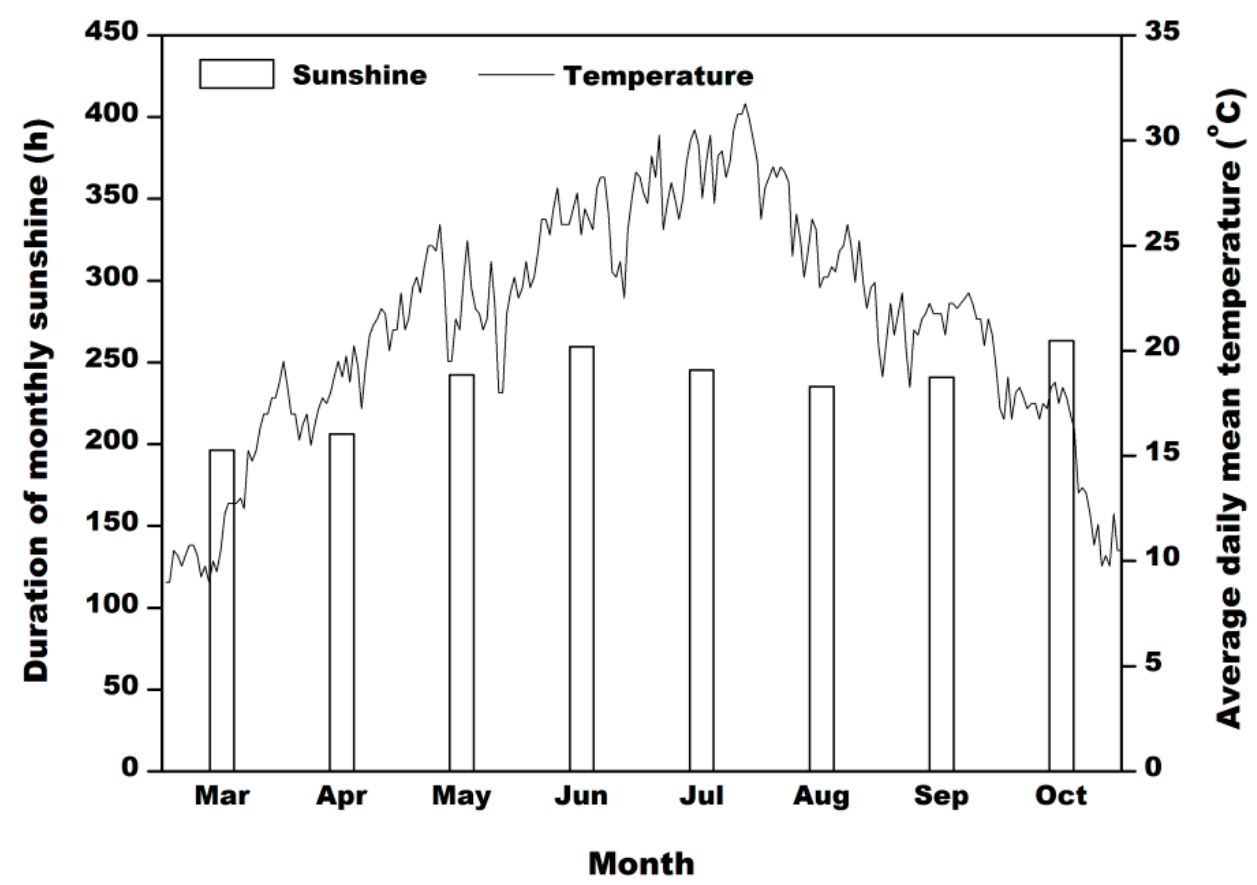

Figure 1. Average daily mean temperature and duration of monthly sunshine during the crop growth period at Moyu County. Data are the averages for 2015, 2016, and 2017 (source: China Meteorological Administration).

The soil type at the study site is a gray desert soil typical of the region. The soil was analyzed before sowing. The chemical properties of the $0-30 \mathrm{~cm}$ soil layer were as follows: extracted mineral nitrogen $11.09 \mathrm{mg} \mathrm{kg}^{-1}, \mathrm{pH}\left(\mathrm{H}_{2} \mathrm{O}\right) 7.73$, soil density $1.39 \mathrm{~g} \mathrm{~cm}^{-3}$, Olsen P $16.97 \mathrm{mg} \mathrm{kg}^{-1}$, $\mathrm{NH}_{4} \mathrm{OAc}$-extracted potassium $76.33 \mathrm{mg} \mathrm{kg}^{-1}$, and organic matter $12.7 \mathrm{~g} \mathrm{~kg}^{-1}$.

\subsection{Experimental Design}

The experiment applied three rice planting methods during three cropping seasons $(2015,2016$, and 2017), namely transplanting (TR), broadcast sowing (BS), and sowing in line (SL). A randomized block design with three replicates was used. There were nine plots in total, and the area of each plot was $10 \mathrm{~m} \times 8 \mathrm{~m}$.

Seeds of rice 'XD11' (Japonica) were obtained from the Xinjiang Academy of Agricultural Sciences, China. The seedlings for the TR treatment were raised in early April in each year of the experiment. Transplanting of seedlings in the TR treatment and sowing of seeds in the SL and BS treatments were carried out from 6-8 May of each year.

The seeding quantity for TR in the nursery and for SL and BS in the field were 90, 225, and $375 \mathrm{~kg} \mathrm{ha}^{-1}$, respectively (Table 1). In the TR treatment, seedlings were transplanted with spacing of $25 \mathrm{~cm} \times 10 \mathrm{~cm}$. Seeding in the SL treatment was carried out using small tractors, with a row spacing of $14 \mathrm{~cm}$. In the BS treatment, artificial sowing was used.

Table 1. Details of the treatments applied in the experiment.

\begin{tabular}{ccc}
\hline Planting Methods & Seeding Quantity $\left.\mathbf{~ ( k g ~ h a ~}^{\mathbf{- 1}}\right)$ & Planting Spacing $\mathbf{( c m )}$ \\
\hline BS & 375 & - \\
SL & 225 & 14 \\
TR & 90 & $25 \times 10$ \\
\hline
\end{tabular}

Note: BS, broadcast sowing; SL, sowing in line; TR, transplanting.

Fertilizer application referred to common practice by farmers. As base fertilizer, $250 \mathrm{~kg} \mathrm{ha}{ }^{-1}$ of diammonium phosphate and $200 \mathrm{~kg} \mathrm{ha}^{-1}$ of potassium sulfate were applied before transplanting in TR and before sowing in SL and BS. In June, four doses of nitrogen 
fertilizer were applied at $90 \mathrm{~kg}$ urea ha ${ }^{-1}$, and 120 and $60 \mathrm{~kg}_{\text {urea ha }}{ }^{-1}$ were applied in July and mid-August, respectively, for all three planting methods. In each treatment, weeds were removed by hand.

\subsection{Plant Harvest}

Given that the middle and late developmental stages of rice have the greatest impact on rice yield [21], we conducted three samplings of rice plants in mid-August, early September, and late September, respectively.

At each sampling time point, $1 \mathrm{~m}^{2}$ of rice samples per plot were collected and the leaf area index was measured. The sampled plants were divided into leaves, stems, reproductive organs, and roots. All samples were killed at $90^{\circ} \mathrm{C}$ for $30 \mathrm{~min}$, then dried at $70{ }^{\circ} \mathrm{C}$ until a constant weight was attained.

Before harvesting, plants within a $1 \mathrm{~m}^{2}$ area per plot were sampled randomly and the number of plants, number of panicles, number of spikelets per panicle, and 1000-grain weight were determined. Theoretical grain yield was calculated on the basis of all harvested plants in each plot. Then the plants within a $2 \mathrm{~m}^{2}$ area per plot were harvested, the grains were weighed, and the harvest index $(\mathrm{HI})$ and actual yield per unit area $\left(\mathrm{kg} \mathrm{ha}^{-1}\right)$ was calculated.

\subsection{Data Analysis}

The data were analyzed using one-way analysis of variance using SAS version 8.0 software (SAS Institute, Cary, NC, USA, 1998). Means among the planting methods were compared based on the least significant difference at the 0.05 level of significance. A correlation analysis between rice yield and its components was performed. All data were the averages of the results for the 3 years of the experiment.

\section{Results}

\subsection{Yield and Its Components}

Significant differences in grain yield under the three planting methods were observed (Table 2). Grain yield was highest under TR $\left(10,390.0 \mathrm{~kg} \mathrm{ha}^{-1}\right)$, followed by SL (9105.2 $\left.\mathrm{kg} \mathrm{ha}^{-1}\right)$, and lowest under BS (7790.7 kg ha $\left.{ }^{-1}\right)$. Among the four yield components measured, the effective panicle number per $\mathrm{m}^{2}$ was highest under SL, but the difference from that of TR was not significant. The number of spikelets per panicle under TR was significantly higher (203) than that of SL (160) and BS (146). The 1000-grain weight was lowest under TR among the three planting methods, whereas the percentage seed set was highest under BS.

Table 2. Yield and yield components of rice plants under three planting methods.

\begin{tabular}{ccccccc}
\hline \multirow{2}{*}{$\begin{array}{c}\text { Planting } \\
\text { Methods }\end{array}$} & $\begin{array}{c}\text { Effective Panicle } \\
\text { Number per } \mathbf{~ m}^{\mathbf{2}}\end{array}$ & $\begin{array}{c}\text { Spikelets per } \\
\text { Panicle }\end{array}$ & $\begin{array}{c}\text { Percentage } \\
\text { Seed Set (\%) }\end{array}$ & $\begin{array}{c}\text { 1000-Grain } \\
\text { Weight (g) }\end{array}$ & Theoretical & Yield (kg ha $\left.{ }^{-1}\right)$ \\
\hline BS & $295 \mathrm{~b}$ & $146 \mathrm{~b}$ & $95.5 \mathrm{a}$ & $23.8 \mathrm{ab}$ & $8251.5 \mathrm{c}$ & $7790.7 \mathrm{c}$ \\
SL & $332 \mathrm{a}$ & $160 \mathrm{~b}$ & $89.6 \mathrm{~b}$ & $25.4 \mathrm{a}$ & $10,278.0 \mathrm{~b}$ & $9105.2 \mathrm{~b}$ \\
TR & $324 \mathrm{a}$ & $203 \mathrm{a}$ & $91.0 \mathrm{~b}$ & $22.7 \mathrm{~b}$ & $11,538.0 \mathrm{a}$ & $10,390.0 \mathrm{a}$ \\
\hline
\end{tabular}

Note: In the 'Effective panicle number' column, 'Effective' indicates the number of panicles per $\mathrm{m}^{2}$ that contained rice seeds at harvest. BS, broadcast sowing; SL, sowing in line; TR, transplanting. Means in rows followed by different letters are significantly different at $p<0.05$ $(n=9)$.

Correlation analysis showed that yield was negatively correlated with percentage seed set and 1000-grain weight (Table 3), but was positively correlated with the number of effective panicles per $\mathrm{m}^{2}$ and number of spikelets per panicle. The correlation of yield with number of spikelets per panicle was statistically significant $(p<0.05)$. 
Table 3. Correlation coefficients between yield and yield components.

\begin{tabular}{ccccc}
\hline Yield Components & \multicolumn{3}{c}{ Correlation Coefficient } \\
\cline { 2 - 5 } & $\mathbf{x}_{\mathbf{2}}$ & $\mathbf{x}_{\mathbf{3}}$ & $\mathbf{x}_{\mathbf{4}}$ & $\mathbf{y}$ \\
\hline Effective panicle number per $\mathrm{m}^{2}\left(\mathrm{x}_{1}\right)$ & -0.0206 & 0.6226 & -0.1696 & 0.5572 \\
Spikelets per panicle $\left(\mathrm{x}_{2}\right)$ & & 0.7674 & -0.4338 & $0.7952^{*}$ \\
Seed setting rate $\left(\mathrm{x}_{3}\right)$ & & & -0.5645 \\
1000-grain weight $\left(\mathrm{x}_{4}\right)$ & & & -0.4365 \\
\hline
\end{tabular}

${ }^{*} p<0.05$.

The number of plants per unit area under BS and SL was higher than that under TR (Figure 2). However, the number of effective plants that formed a spike was highest under TR among the three planting methods; therefore, the ratio of effective plants to total plants was higher under TR. Thus, under BS and SL (especially under BS), plants formed a higher number of ineffective tillers than those under TR.

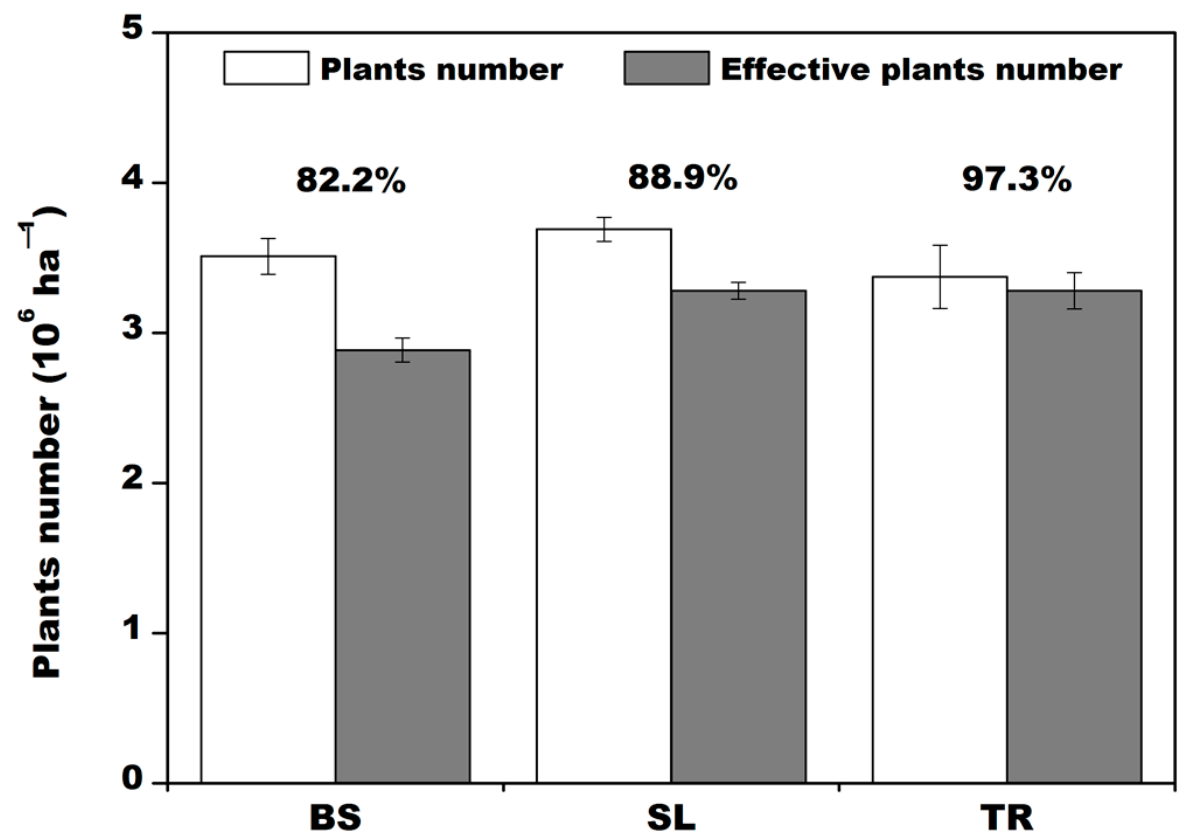

Figure 2. Total number of plants and number of effective plants per hectare of rice plants under three planting methods. The value above the columns represents the ratio of effective plants to total plants. BS, broadcast sowing; SL, sowing in line; TR, transplanting.

\subsection{Growth}

At three growth stages, the plant dry matter under TR was higher than that of SL, and that under BS was the lowest at each stage (Figure 3). With progression of the growing season, the shoot dry matter increased gradually in all three treatments, whereas the increase in root dry matter differed among the three planting methods. The increase in root dry matter was greater under BS than that under SL, whereas root dry matter under TR showed little change after mid-August.

Given the differences in distribution of shoot and root dry matter under the different planting methods (Figure 3), the ratio of shoot dry matter to root dry matter differed notably among the treatments; the ratio was greater under TR than that under SL, and the ratio under BS was the lowest. The differences were most distinct at advanced stages of development (Figure 4). 


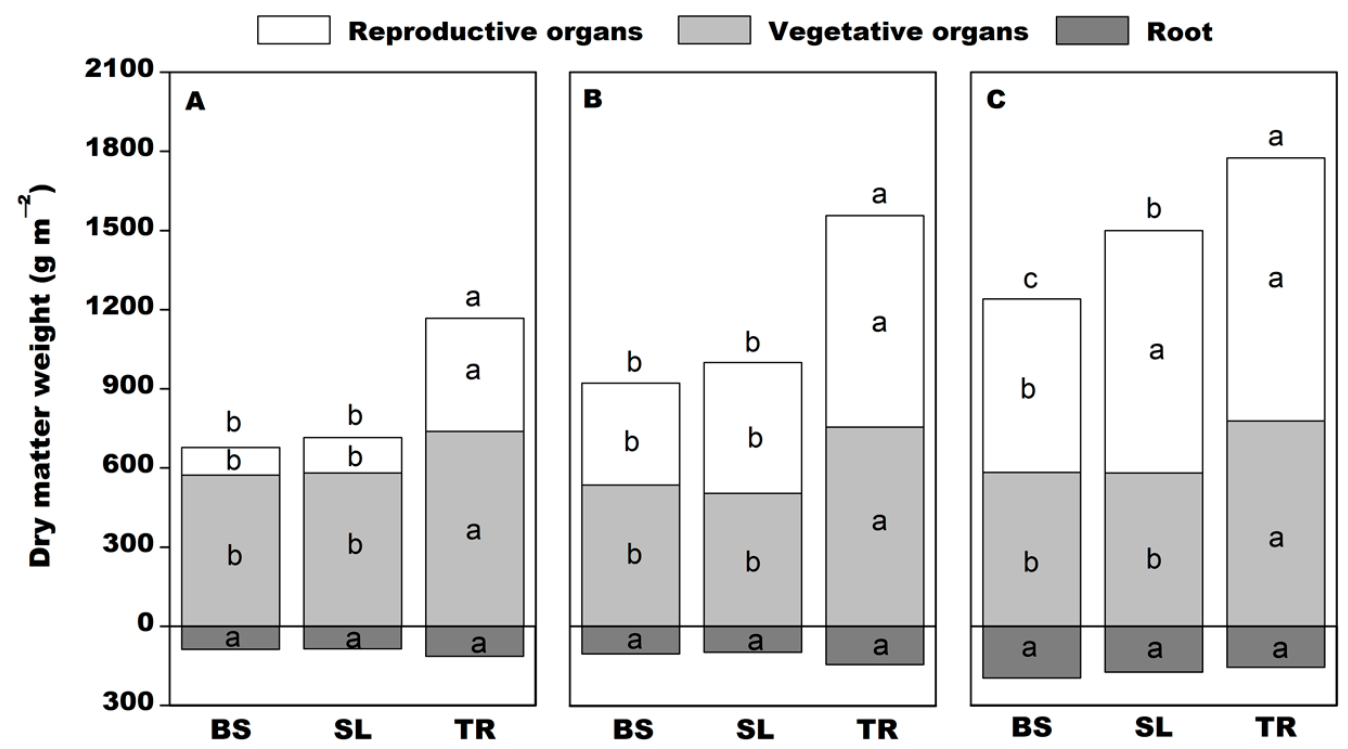

Figure 3. Dry matter weight of rice plants under three planting methods at three growth stages. Plants were sampled in (A) mid-August, (B) early September, and (C) late September. BS, Broadcast sowing; SL, sowing in line; TR, transplanting. For each plant organ, means with a different lower-case letter were significantly different between the planting methods at the same sampling time at $p<0.05$ $(n=9)$.
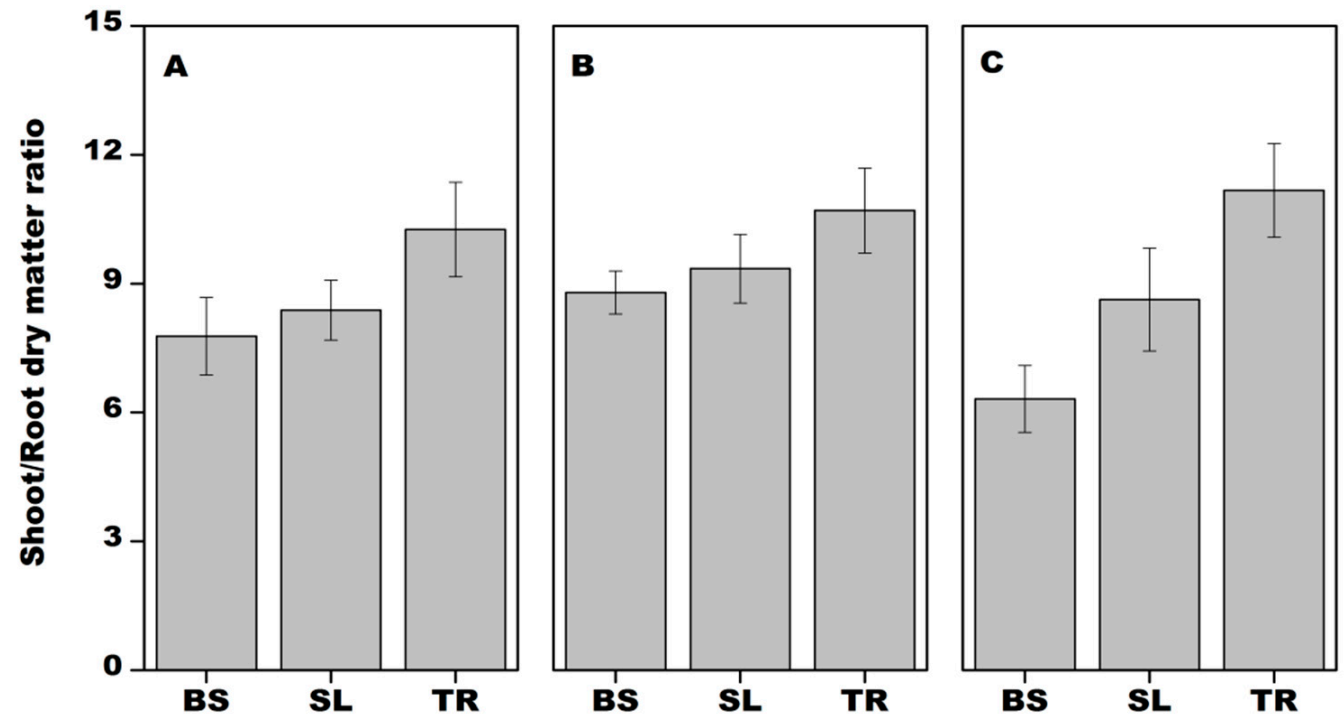

Figure 4. Ratio of shoot dry matter to root dry matter of rice plants under three planting methods at three growth stages. Plants were sampled in (A) mid-August, (B) early September, and (C) late September. BS, Broadcast sowing; SL, sowing in line; TR, transplanting.

From the heading stage, the leaf area index of rice plants showed a decreasing trend with progression of the growing season (Figure 5). In general, the leaf area index under BS and TR was higher than that under SL. In mid-August and early September, the leaf area index under TR was higher than that under BS, especially in early September, but thereafter decreased rapidly. 


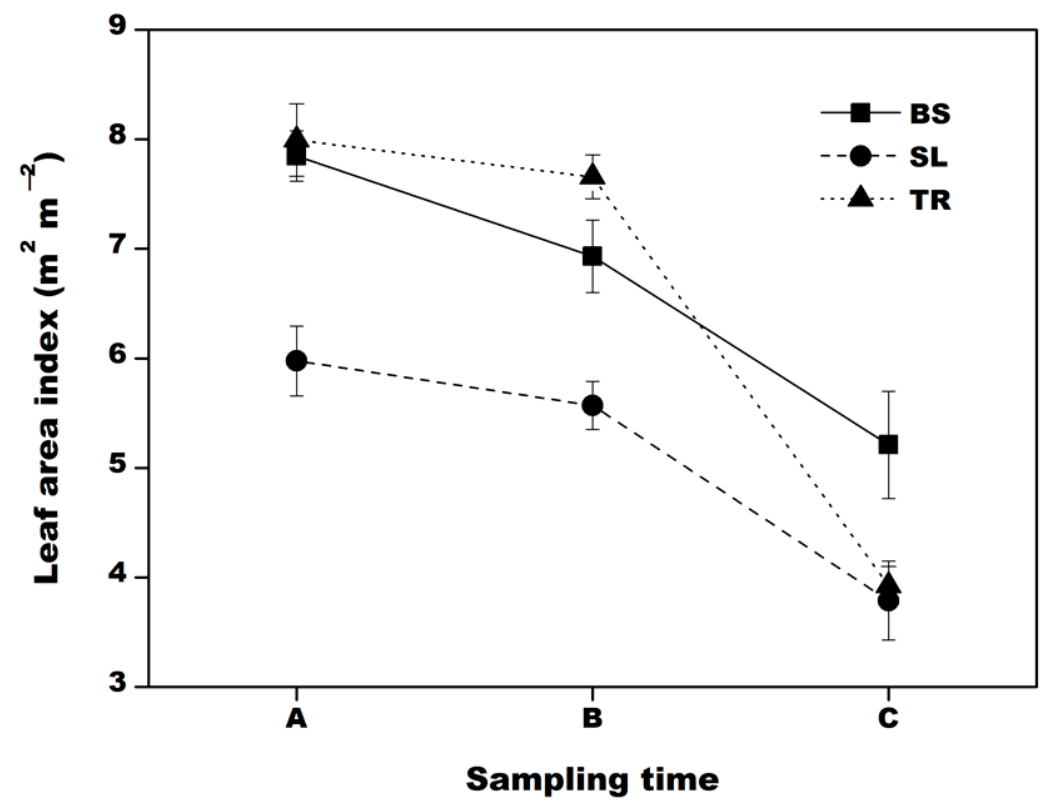

Figure 5. Leaf area index of rice plants under three planting methods at three growth stages. Plants were sampled in (A) mid-August, (B) early September, and (C) late September. BS, Broadcast sowing; SL, sowing in line; TR, transplanting.

Little difference in harvest index (HI) was observed among rice plants under the different planting methods (Figure 6).

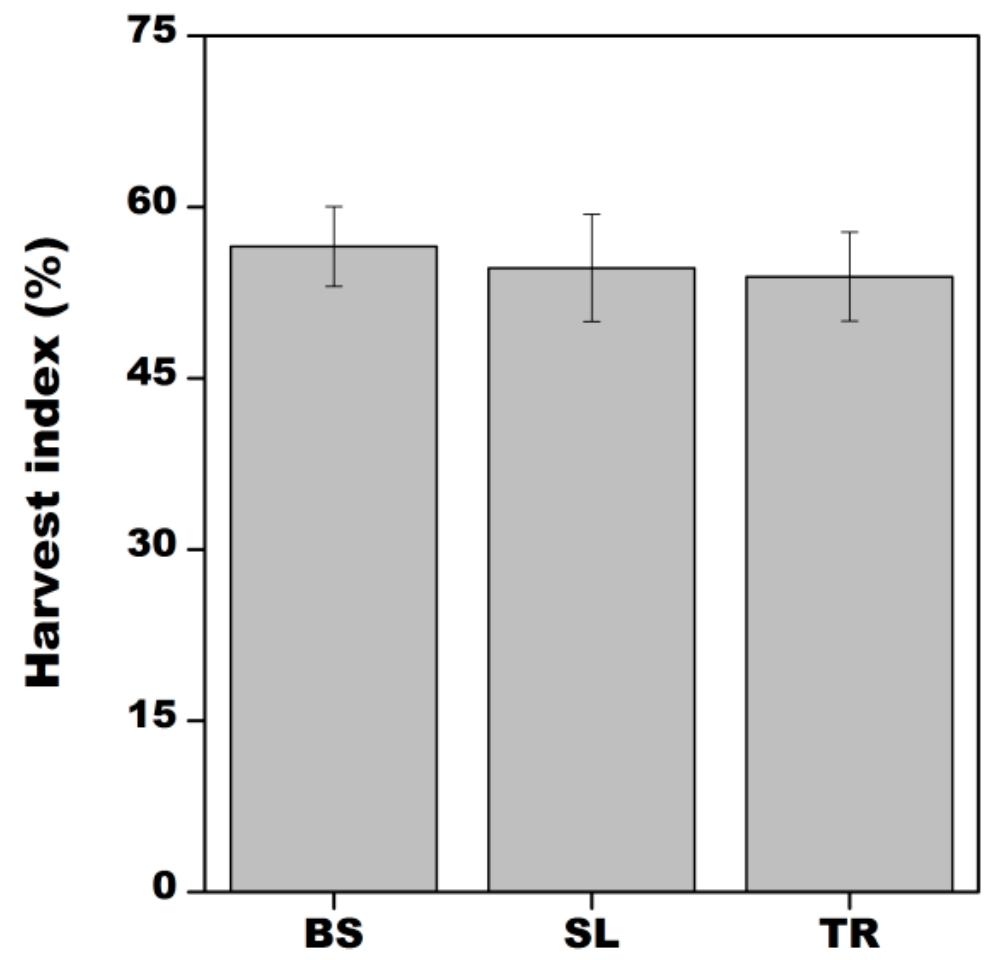

Figure 6. Harvest index of rice plants under three planting methods. BS, Broadcast sowing; $\mathrm{SL}$, sowing in line; TR, transplanting.

Given that TR requires the raising of seedlings, the vegetative growth period under this planting method was longer at 107 days, whereas those under BS and SL were 97 and 89 days, respectively (Figure 7). The TR treatment also showed the longest reproductive phase of 60 days, followed by SL ( 54 days), whereas the reproductive phase was shortest 
under BS (49 days). Therefore, with regard to the total growth period, the maximum length was 167 days under TR, whereas those under BS and SL were 146 and 143 days, respectively. Within each of the vegetative and reproductive phases, plant growth and development under TR was accelerated compared with that under SL, and that under BS was the slowest. For example, in mid-August, when grain filling was initiated in the TR treatment, plants in the BS treatment were at the heading stage.

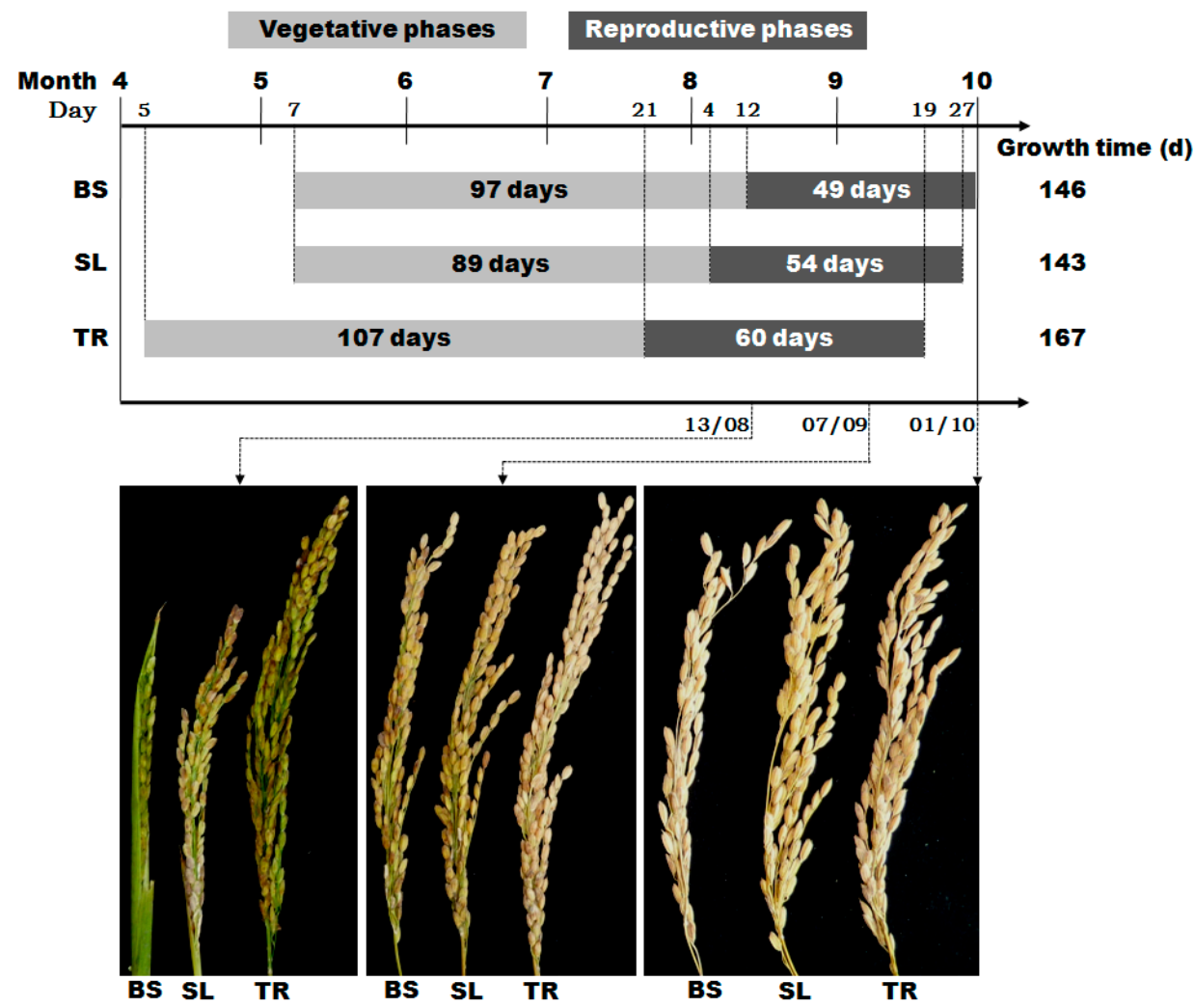

Figure 7. The growth period and panicle morphology of rice plants under three planting methods. BS, Broadcast sowing; SL, sowing in line; TR, transplanting.

\subsection{Cost and Income}

In rice production, the largest input cost is labor. Differences in labor cost were pronounced among the three planting methods. The labor input under TR was distinctly higher than that under BS, whereas that under SL was the lowest (Table 4). In addition, marked differences were observed in the cost of seed input, which followed the rank order BS > SL > TR. Other inputs, including fertilizers, pesticides, machinery, and irrigation, showed little difference among the three planting methods.

Table 4. Production cost of rice under three planting methods.

\begin{tabular}{cccccccc}
\hline \multirow{2}{*}{$\begin{array}{c}\text { Planting } \\
\text { Methods }\end{array}$} & \multicolumn{7}{c}{ Cost of Production (US Dollars ha ${ }^{-1}$ ) } \\
\cline { 2 - 8 } & Seeds & Labor & Fertilizer & Pesticides & Mechanics & Irrigation & Others \\
\hline BS & 338.35 & 517.29 & 293.23 & 186.02 & 180.45 & 100.00 & 12.03 \\
SL & 203.01 & 460.90 & 293.23 & 186.02 & 263.16 & 100.00 & 12.03 \\
TR & 81.20 & 827.07 & 315.79 & 186.02 & 190.98 & 129.32 & 65.41 \\
\hline
\end{tabular}

Note: BS, Broadcast sowing; SL, sowing in line; TR, transplanting. Seeds: the quantity of TR, SL and BS is 90, 225 and $375 \mathrm{~kg} /$ ha respectively. Labor: compared with SL and BS, TR requires more labor to transplant seedlings. Fertilizer: under TR, fertilizer also needs to be applied when raising seedlings and the cost is slightly higher than the SL and BS. Mechanics: there is little difference between BS and TR, while SL requires machinery for sowing. Irrigation: TR needs irrigation in the process of seedling raising, so it is higher than the BS and SL. Others: TR has more investment in the process of seedling raising (mainly the construction of seedling-raising sheds). 
The total production cost was highest under TR, which was 1795.8 US dollars ha ${ }^{-1}$, followed by BS (1627.4 US dollars ha ${ }^{-1}$ ), and the lowest was under SL (1518.3 US dollars ha ${ }^{-1}$ ) (Table 5). The income under TR was greater than that under SL and BS, and net income showed the same trend, whereas the cost under TR and BS was higher than that under SL. The benefit-to-cost ratio was highest under SL, followed by TR, and that under BS was the lowest.

Table 5. Cost of production, income, and benefit-to-cost ratio of rice production under three planting methods.

\begin{tabular}{ccccc}
\hline \multirow{2}{*}{$\begin{array}{c}\text { Planting } \\
\text { Methods }\end{array}$} & \multicolumn{2}{c}{ Cost and Income (US Dollars ha ${ }^{-\mathbf{1}}$ ) } & Benefit-Cost \\
\cline { 2 - 4 } & $\begin{array}{c}\text { Cost of } \\
\text { Production }\end{array}$ & Income & Net Income & \\
\hline BS & 1627.4 & 3280.3 & 1652.9 & 2.02 \\
SL & 1518.3 & 3833.8 & 2315.4 & 2.52 \\
TR & 1795.8 & 4374.7 & 2578.9 & 2.44 \\
\hline
\end{tabular}

Note: 'Benefit-to-cost ratio' indicates the ratio of 'income' to 'cost of production'. BS, Broadcast sowing; SL, sowing in line; TR, transplanting.

\section{Discussion}

4.1. The Increased Number of Spikelets per Panicle Is the Most Important Factor in the High Yield of Transplanted Rice

Crop yield formation is the process of accumulation and distribution of dry matter. In rice, grain yield is the product of shoot dry matter and HI. The increase in shoot dry matter or HI or both parameters can theoretically increase yield [24]. In terms of growth conditions, Peng believed that under favorable light, temperature, water, and fertilizer conditions, hybrid rice increased yield by increasing the photosynthetic rate and the accumulation of shoot dry matter in the population, and under unfavorable conditions, yield could be maintained by achieving high shoot dry matter transport efficiency and high HI [21]. In the present study, we observed that the HI showed almost no difference under the three planting methods (Figure 6), whereas shoot dry matter (Figure 3) and yield (Table 2) were highest under TR. Yield increased with the increase in shoot dry matter accumulation, which supported the above-mentioned conclusion.

The high yield of hybrid rice is attained mainly from the accumulation of photosynthate after heading, but shows no significant correlation with accumulation of dry matter at the jointing stage and is essentially attributable to increased leaf area and prolonged leaf function [25]. In the present study, using the same rice cultivar, different planting methods essentially created different growth conditions. Compared with BS and SL, the leaf area index of TR remained higher for the majority of the growth period (Figure 5), which provided a guarantee for accumulation of dry matter. In general, we consider that there are two main reasons for the greater shoot dry matter production under TR compared with that under BS or SL (Figure 8). (1) Compared with TR, the BS and SL treatments (especially BS) were more densely planted (Figure 2). The high plant density results in enhanced competition for nutrient resources [26]. Therefore, to obtain greater amounts of nutrient resources, plants growing under BS and SL, especially the former, will allocate higher quantities of photosynthates to the roots, increasing root dry matter production, and thus affecting shoot growth (Figure 3). The lower shoot to root ratio and effective plants to total plants ratio under BS support this inference (Figures 2 and 4). (2) The growth period under TR is longer than that under BS or SL (for the vegetative and reproductive growth phases; Figure 7). Therefore, photosynthetic activity is prolonged, which is beneficial for the accumulation of dry matter products. The duration of grain filling is considered to be an important factor in determination of grain yield. It is generally believed that high yield in temperate environments is mainly due to longer growth duration and greater solar radiation $[27,28]$. The longer growth period will result in enhanced dry matter production, thereby contributing to improved grain filling and higher grain yield. Yoshida considered that the increase in grain weight showed a linear relationship to the increase in effective 
grain filling duration [24]. A previous study on the contribution to yield of grain filling period and grain yield showed that the grain yield of different genotypes was mainly determined by grain filling rate [29].

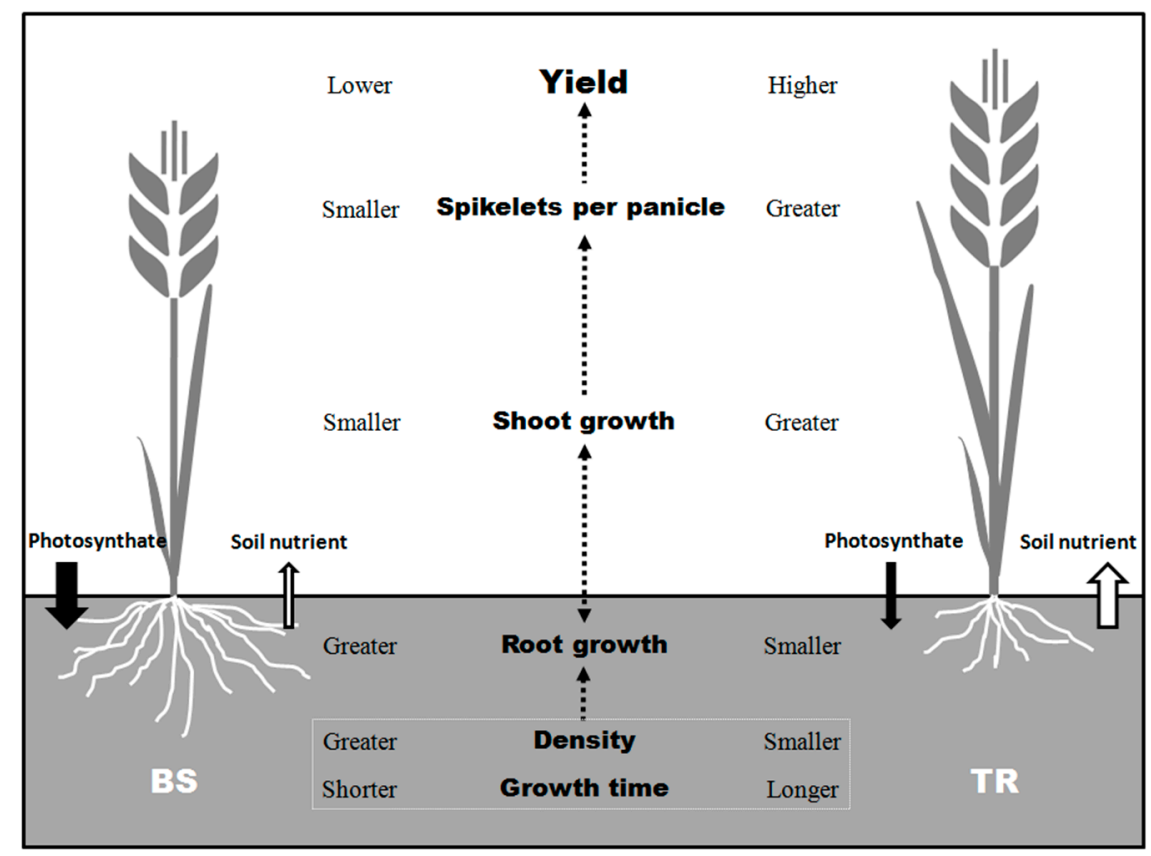

Figure 8. Schematic diagram of differences in rice yield attained under different cultivation methods. Compared with the broadcast sowing (BS) method, the planting density of transplanted (TR) rice is lower, the growth period is longer, and the competition from roots for photosynthetic products and soil nutrients is weak. Therefore, under TR, root growth is reduced, but accumulation of shoot dry matter is increased, the number of spikelets per panicle is enhanced, and yield is improved.

With regard to yield components, it is difficult to increase the percentage seed set and 1000-grain weight owing to their stability [21]. Therefore, the number of spikelets per $\mathrm{m}^{2}$, which represents the sink size, is the most important factor that determines the yield of a cereal crop [30]. When growing in a high-yield, stress-free environment, the sink size can be increased by increasing the number of panicles or number of spikelets per panicle or both parameters [31]. In the present study, no significant difference in the 1000-grain weight of rice under the three planting methods was observed, but the percentage seed set was higher under TR than under BS or SL (Table 2). Correlation analysis indicated that the higher yield under TR reflected the higher number of effective panicles and number of spikelets per panicle (which was strongly correlated with yield; Table 3). Panicle number per $\mathrm{m}^{2}$ and number of spikelets per panicle are negatively correlated [24]; therefore, their balance is important for obtaining the largest sink and only when the panicle number remains unchanged can a higher number of spikelets per panicle be selected to increase the sink size [23]. In rice, the number of panicles per $\mathrm{m}^{2}$ and the number of spikelets per panicle are strongly correlated with accumulation of dry matter at the beginning of heading [31], and grain filling to a large extent depends on accumulation of dry matter from flowering to maturity [24]. These observations indicate that the higher yield attained under TR stems from the increase in dry matter production and thus the enhanced number of spikelets per panicle.

\subsection{SL Can Achieve Higher Returns in Rice Production}

The traditional rice planting method based on artificial transplanting has failed to meet the needs of social and economic development. There are two main reasons for this. (1) In the traditional transplanting system, the demand for water resources is high. In many areas, surface water and groundwater resources are shrinking, and water has become a 
limiting factor in rice production [32]. (2) The traditional rice transplanting method carries a higher labor cost because of the need for raising seedlings and artificial transplanting. Therefore, although the yield is often higher, the acquisition of substantial water resources and the greater labor cost reduce the profitability of rice production under TR [33]. It is therefore imperative to develop efficient and labor-saving rice planting methods. Direct seeding can significantly reduce rice production costs [34]. Since the 1950s, direct seeding has been one of the main methods of rice planting [35]. In recent years, in several countries of Southeast Asia, the transformation of rice planting method from transplanting to direct seeding has begun [15]. In the present study, we compared the BS and SL direct-seeding methods. The present results suggested that SL is a more advantageous method for rice production: (1) although yield was lower under SL than that under TR, the difference was relatively small (Table 2), whereas the SL yield was significantly higher than that under BS; (2) the cost of SL is significantly lower (compared with BS, the seeding quantity was reduced; compared with TR, labor input was reduced (Table 4)); and (3) the benefit-to-cost ratio was higher under SL than under BS and TR (Table 5).

Additional factors other than yield also determine the optimal rice planting method, such as factors linked to the local economy and labor resources. Worldwide, it is beneficial to use TR in areas with low labor costs and sufficient water resources, whereas direct seeding is more suitable in areas with high labor costs and insufficient water resources [35]. In economically developed rice-producing countries, rice planting methods have undergone transformation from artificial transplanting to mechanical direct seeding or mechanical transplanting. In China, the area of artificial transplanting is declining, but presently accounts for $50 \%$ of the rice production area. Artificial transplanting is mainly practiced in areas with high population density, low per capita cultivated land area, small-scale farmers, and sufficient labor force. The area of direct-seeding rice production increased from $2 \%$ in 2000 to about $11 \%$ in 2009 [9].

Although many studies have shown that direct seeding of rice is superior to transplanting in many aspects, direct seeding has been practiced for an extended period in many areas, but has not been popularized [36,37]. In 2007, about only $23 \%$ of the world's rice is produced using a direct-seeding method [38]. This is because direct seeding still faces a number of challenges. Farooq et al. provide a detailed summary of these challenges, including the invasion of weeds, relatively low yield, the cultivation of specialized cultivars, low ripening rate, nutrient resource management, disease and insect pests, and water management [8]. The present results suggest that under the conditions of SL, compared with TR, management of nutrient resources may be the most important factor compared with other challenges. As already mentioned, compared with TR, low shoot dry matter production and number of spikelets per panicle are the main factors responsible for the low yield of direct-seeded rice. These factors are closely associated with the higher planting density and reduced capacity to meet nutrient demands (consequently, root growth is promoted by the reduction in shoot growth). Determination of the appropriate planting density and formulation of an effective strategy for management of nutrient resources compatible with the local climatic conditions of the region are crucial requirements to improve the yield and income of direct-seeded rice, especially when using the SL planting method.

\section{Conclusions}

In this study, rice yield was highest under TR. The yield of rice depends on shoot dry matter production and the HI. Given that the three planting methods showed almost no differences in HI, the differences in yield reflected the shoot dry matter production. The three planting methods showed greatest divergence in planting density and growth period. The planting density under TR was the lowest, so competition for soil nutrient resources was relatively weak. The TR method included 1 month for raising seedlings; thus, the growth period was longer and the duration of grain filling was prolonged compared with those under SL and BS. These two factors contributed to the significantly higher number of spikelets per panicle under TR than that under SL and BS, and ultimately to the higher 
yield. However, given the substantial investment in labor required, the benefit-to-cost ratio under TR was not the highest. The yield of SL was lower than that under TR, but was distinctly higher than that under BS, and costs were the lowest under SL among the three planting methods; thus, the benefit-to-cost ratio of SL was the highest. Therefore, with increasing labor costs worldwide, SL represents a more profitable method of rice planting.

Author Contributions: W.M. have contributed in developing the research ideas, analyzing the data, conducting the research and writing the manuscript; B.A. have contributed in investigation; X.X. have contributed in analyzing the data and writing the manuscript. All authors have read and agreed to the published version of the manuscript.

Funding: This research was funded by the "Western young scholars" project of the Chinese Academy of Sciences (Grant NO. 2019-XBQNXZ-A-006), and the basic research funding of non-profit scientific research institutes in the Xinjiang Uygur Autonomous Region (Grant NO. KY2019007).

Data Availability Statement: Data is contained within the article.

Conflicts of Interest: The authors declare no conflict of interest.

\section{References}

1. Huang, M.; Zou, Y.B.; Jiang, P.; Xia, B.; Md, I.; Ao, H.J. Relationship between grain yield and yield components in super hybrid rice. Agric. Sci. China 2011, 10, 1537-1544. [CrossRef]

2. Normile, D. Reinventing rice to feed the world. Science 2008, 321, 330-333. [CrossRef] [PubMed]

3. Cassman, K.G.; Peng, S.; Olk, D.C.; Ladha, J.K.; Reichardt, W.; Dobermann, A.; Singh, U. Opportunities for increased nitrogen use efficiency from improved recourse management in irrigated rice system. Field Crops Res. 1998, 56, 7-38. [CrossRef]

4. Peng, S.B.; Khush, G.S.; Virk, P.; Tang, Q.; Zou, Y. Progress in ideotype breeding to increase rice yield potential. Field Crops Res. 2008, 108, 32-38. [CrossRef]

5. Huang, M.; Tang, Q.Y.; Ao, H.J.; Zou, Y.B. Yield potential and stability in super hybrid rice and its production strategies. J. Integr. Agric. 2017, 16, 1009-1017. [CrossRef]

6. Peng, S.B. The importance of improved crop management to world rice production. Crop Res. 2008, 22, $207-208$.

7. Dawe, D. Increasing water productivity in rice-based systems in Asia-Past trends, current problems, and future prospects. Plant Prod. Sci. 2005, 8, 221-230. [CrossRef]

8. Farooq, M.; Siddique, K.H.M.; Rehman, H.; Aziz, T.; Lee, D.J.; Wahid, A. Rice direct seeding: Experiences, challenges and opportunities. Soil Tillage Res. 2011, 111, 87-98. [CrossRef]

9. Zhang, Y.P.; Zhu, D.F.; Xiong, H.; Chen, H.Z.; Xiang, J.; Lin, X.Q. Development and transition of rice planting in China. Agric. Sci. Tech. 2012, 13, 1270-1276.

10. Wang, Y.X.; Wang, Y.J. Current situation and development countermeasures of rice production in Zhejiang Province. Zhejiang Agric. Sci. 2019, 60, 177-179, 183.

11. Rana, M.M.; Mamun, M.A.A.; Zahan, A.; Ahmed, M.N.; Mridha, M.A.J. Effect of planting methods on the yield and yield attributes of short duration Aman rice. Am. J. Plant Sci. 2014, 5, 251-255. [CrossRef]

12. San-oh, Y.; Mano, Y.; Ookawa, T.; Hirasawa, T. Comparison of dry matter production and associated characteristics between direct-sown and transplanted rice plants in a submerged paddy field and relationships to planting patterns. Field Crops Res. 2004, 87, 43-58. [CrossRef]

13. Hayashi, S.; Kamoshita, A.; Yamagishi, J.; Kotchasatit, A.; Jongdee, B. Genotypic differences in grain yield of transplanted and direct-seeded rainfed lowland rice (Oryza sativa L.) in northeastern. Thailand Field Crops Res. 2007, 102, 9-21. [CrossRef]

14. Naklang, K.; Fukai, S.; Nathabut, K. Growth of rice cultivars by direct seeding and transplanting under upland and lowland conditions. Field Crops Res. 1996, 48, 115-123. [CrossRef]

15. Pandey, S.; Velasco, L. Economics of direct seeding in Asia: Patterns of adoption and research priorities. In Direct Seeding: Research Strategies and Opportunities; Pandey, S., Mortimer, M., Wade, L., Tuong, T.P., Lopes, K., Hardy, B., Eds.; International Rice Research Institute: Los Baños, Philippines, 2002.

16. Chen, S.; Cai, S.G.; Chen, X.; Zhang, G.P. Genotypic differences in growth and physiological responses to transplanting and direct seeding cultivation in rice. Rice Sci. 2009, 16, 143-150. [CrossRef]

17. Javaid, T.; Awan, I.U.; Baloch, M.S.; Shah, I.H.; Nadim, M.A.; Khan, E.A.; Khakwani, A.A.; Abuzar, M.R. Effect of planting methods on the growth and yield of coarse rice. J. Anim. Plant Sci. 2012, 22, 358-362.

18. Raj, S.K.; Mathew, R.; Jose, N.; Leenakumary, S. Enhancing the productivity and profitability in rice cultivation by planting methods. Madras Agric. 2012, 99, 759-761.

19. Rana, I.A.; Nadeem, I.; Muhammad, U.S.; Muhammad, A. Effect of different planting methods on economic yield and grain quality of rice. Int. J. Agric. Appl. Sci. 2012, 4, 28-34.

20. Yoshida, H.; Takeshi, H.; Tatsuhiko, S. A model explaining genotypic and environmental variation of rice spikelet number per unit area measured by cross-locational experiments in Asia. Field Crops Res. 2006, 97, 337-343. [CrossRef] 
21. Peng, S.B.; Bouman, B.; Visperas, R.M.; Castaneda, A.; Nie, L.X.; Park, H.K. Comparison between aerobic and flooded rice in the topics: Agronomic performance in an eight-season experiment. Field Crops Res. 2006, 96, 252-259. [CrossRef]

22. Katsura, K.; Maeda, S.; Lubis, I.; Horie, T.; Cao, W.; Shiraiwa, T. The high yield of irrigated rice in Yunnan, China 'A cross location analysis'. Field Crops Res. 2008, 107, 1-11. [CrossRef]

23. Ying, J.F.; Peng, S.B.; He, Q.R.; Yang, H.; Yang, C.D.; Visperas, R.M.; Cassman, K.G. Comparison of high-yield rice in tropical and subtropical environments I. Determinants of grain and dry matter yields. Field Crops Res. 1998, 57, 71-84. [CrossRef]

24. Yoshida, S. Fundamentals of Rice Crop Science; International Rice Research Institute: Los Baños, Philippines, 1981.

25. Wu, W.G.; Zhang, H.C.; Qian, Y.F.; Cheng, Y.; Wu, G.C.; Zhai, C.Q.; Dai, Q.G. Analysis on dry matter production characteristics of super hybrid rice. Rice Sci. 2008, 15, 110-118. [CrossRef]

26. Dou, Z.; Li, Y.; Guo, H.; Chen, L.; Jiang, J.; Zhou, Y.; Xu, Q.; Xing, Z.; Gao, H.; Zhang, H. Effects of mechanically transplanting methods and planting densities on yield and quality of Nanjing 2728 under Rice-Crayfish continuous production system. Agronomy 2021, 11, 488. [CrossRef]

27. Yang, W.H.; Peng, S.B.; Dionisio-Sese, M.L.; Laza, R.C.; Visperas, R.M. Grain filling duration, a crucial determinant of genotypic variation of grain yield in field-grown tropical irrigated rice. Field Crops Res. 2008, 105, 221-227. [CrossRef]

28. Bian, J.L.; Xu, F.F.; Han, C.; Qiu, S.; Ge, J.L.; Xu, J.; Zhang, H.C.; Wei, H.Y. Effects of planting methods on yield and quality of different types of japonica rice in northern Jiangsu plain, China. J. Integr. Agric. 2018, 17, 2624-2635. [CrossRef]

29. Jones, D.B.; Peterson, M.L.; Geng, S. Association between grain filling rate and duration and yield components in rice. Crop Sci. 1979, 19, 641-644. [CrossRef]

30. Sorour, F.A.; Ragab, A.Y.; Metwally, T.F.; Shafik, A.A. Effect of planting methods and nitrogen fertilizer rates on the productivity of rice (Oryza sativa L.). J. Agric. Res. 2016, 42, 173-182.

31. Kropff, M.J.; Cassman, K.G.; Peng, S.; Matthews, R.B.; Setter, T.L. Quantitative understanding of yield potential. In Breaking the Yield Barrier; Cassman, K.G., Ed.; International Rice Research Institute: Los Baños, Philippines, 1994; pp. 21-38.

32. Farooq, M.; Wahid, A.; Lee, D.J.; Ito, O.; Siddique, K.H.M. Advances in drought resistance of rice. Crit. Rev. Plant Sci. 2009, 28, 199-217. [CrossRef]

33. Pandey, S.; Velasco, L.E. Economics of alternative rice establishment methods in Asia: A strategic analysis. In Social Sciences Division Discussion Paper; International Rice Research Institute: Los Banõs, Philippines, 1999.

34. Flinn, J.C.; Mandac, A.M. Wet Seeding of Rice in Less Favored Rainfed Environments Working Paper. Agricultural Economics Department, International Rice Research Institute: Los Baños, Philippines, 1986.

35. Pandey, S.; Velasco, L. Trends in crop establishment methods in Asia and research issues. In Rice is Life: Scientific Perspectives for the 21st Century, Proceedings of the World Rice Research Conference, Tsukuba, Japan, 4-7 November 2004; International Rice Research Institute: Manila, Philippines, 2005; pp. 178-181.

36. Bhushan, L.; Ladha, J.K.; Gupta, R.K.; Singh, S.; Tirol-Padre, A.; Saharawat, Y.S.; Gathala, M.; Pathak, H. Saving of water and labor in a rice-wheat system with no-tillage and direct seeding technologies. Agron. J. 2007, 99, 1288-1296. [CrossRef]

37. Farooq, M.; Basra, S.M.A.; Asad, S.A. Comparison of conventional puddling and dry tillage in rice-wheat system. Paddy Water Environ. 2008, 6, 397-404. [CrossRef]

38. Rao, A.N.; Johnson, D.E.; Sivaprasad, B.; Ladha, J.K.; Mortimer, A.M. Weed management in direct-seeded rice. Adv. Agron. 2007, 93, 153-255. 